Article

\title{
Simultaneous Quantification of Three Curcuminoids and Three Volatile Components of Curcuma longa Using Pressurized Liquid Extraction and High-Performance Liquid Chromatography
}

\author{
In-Cheng Chao ${ }^{1}$, Chun-Ming Wang ${ }^{1}$, Shao-Ping Li ${ }^{1}$, Li-Gen Lin ${ }^{1}{ }^{1}$, Wen-Cai Ye ${ }^{2}$ and \\ Qing-Wen Zhang ${ }^{1, *}$ \\ 1 State Key Laboratory of Quality Research in Chinese Medicine, Institute of Chinese Medical Sciences, \\ University of Macau, Macao 999078, China; yqzhou1986@gmail.com (I.-C.C.); cmwang@umac.mo (C.-M.W.); \\ spli@umac.mo (S.-P.L.); ligenl@umac.mo (L.-G.L.) \\ 2 Institute of Traditional Chinese Medicine and Natural Products, Jinan University, Guangzhou 510632, China; \\ chywc@aliyun.com \\ * Correspondence: qwzhang@umac.mo; Tel.: +853-8822-4879
}

Academic Editor: Maria Carla Marcotullio

Received: 21 May 2018; Accepted: 26 June 2018; Published: 28 June 2018

\begin{abstract}
A high-performance liquid chromatography (HPLC) method was investigated for the simultaneous quantification of two chemical types of bioactive compounds in the rhizome of Curcuma longa Linn. (turmeric), including three curcuminoids: Curcumin, bisdemethoxycurcumin, and demethoxycurcumin; and three volatile components: $a r$-turmerone, $\beta$-turmerone, and $\alpha$-turmerone. In the present study, the sample extraction system was optimized by a pressurized liquid extraction (PLE) process for further HPLC analysis. The established HPLC analysis conditions were achieved using a Zorbax SB-C18 column $(250 \mathrm{~mm} \times 4.6 \mathrm{~mm}$ i.d., $5 \mu \mathrm{m})$ and a gradient mobile phase comprised of acetonitrile and $0.4 \%(v / v)$ aqueous acetic acid with an eluting rate of $1.0 \mathrm{~mL} / \mathrm{min}$. The curcuminoids and volatile components were detected at $430 \mathrm{~nm}$ and $240 \mathrm{~nm}$, respectively. Moreover, the method was validated in terms of linearity, sensitivity, precision, stability and accuracy. The validated method was successfully applied to evaluate the quality of twelve commercial turmeric samples.
\end{abstract}

Keywords: HPLC; Curcuma longa; turmeric; curcuminoids; turmerone; quantification

\section{Introduction}

Curcuma longa Linn. (C. longa), belonging to the Zingiberaceae family, is a native plant of southern Asia, mainly India and China. The rhizome of $C$. longa, also called turmeric, has long been used as a spice or food additive and in traditional medicine system in Asia. In traditional Chinese medicine, it is called "Jianghuang", and has been widely used for the treatment of diabetic wounds, hepatic disorders and cardiovascular disease [1]. Phytochemical investigation of turmeric has revealed it contains curcuminoids and volatile oils as the major components [2]. Curcumin and two demethoxy derivatives, demethoxycurcumin and bisdemethoxycurcumin, are the major curcuminoids in turmeric, which have anti-cancer, anti-inflammatory, neuroprotective, anti-Alzheimers and anti-oxidant activities [2-8]. Curcuminoids have always been the focus of drug research. Furthermore, the volatile oil of turmeric is also widely used in cosmetic and health products, and possesses antimicrobial, antifungal, and antiarthritic activities [9-11]. Recently, studies have indicated that turmerones were the active constituents in turmeric oil, and proved their anti-cancer, anti-inflammatory, antiplatelet, 
anti-angiogenic, and neuropharmacological properties [12-16]. Therefore, both curcuminoids and volatile components accounted for the efficacy of turmeric. As such, both kinds of components should be used as markers for an evaluation of the quality of turmeric and the products from turmeric. Many methods, including HPLC or ultra performance liquid chromatography (UPLC) coupled with UV-vis and/or MS detector [17-20], high performance thin layer chromatography (HPTLC) [21], capillary electrophoresis (CE) [22], and microemulsion electrokinetic chromatography [23], have been developed for qualitative and quantitative analysis of curcuminoids in turmeric and its pharmaceutical preparations. Gas chromatography-flame ionization detector (GC-FID) and gas chromatography-mass spectrometry (GC-MS) are the conventional methods used for the analysis of the volatile constituents of turmeric. ar-Turmerone, $\alpha$-turmerone, and $\beta$-turmerone were determined to be the major compounds of the volatile oil $[24,25]$. However, the content of volatile components is only determined by the percentage of the selected ions peak area. Up till now, no method was reported for simultaneous quantitative analysis of major curcuminoids and volatile components in turmeric.

In this paper, an HPLC method coupled with pressurized liquid extraction (PLE) was developed for simultaneous quantification of the two classes of bioactivity components in turmeric, including three curcuminods: Bisdemethoxycurcumin, demethoxycurcumin and curcumin; and three volatile components: ar-turmerone, $\beta$-turmerone and $\alpha$-turmerone (Figure 1). The developed method was successfully applied to evaluate the quality of twelve samples of turmeric.<smiles>O=C(/C=C/c1ccc(O)cc1)CC(=O)/C=C/c1ccc(O)cc1</smiles>

1. bisdemethoxycurcumin (BMC)<smiles>COc1cc(/C=C/C(=O)CC(=O)/C=C/c2ccc(O)cc2)ccc1O</smiles>

2. demethoxycurcumin (DMC)<smiles>COc1cc(/C=C/C(=O)CC(=O)/C=C/c2ccc(O)c(OC)c2)ccc1O</smiles>

3. $\operatorname{curcumin}(\mathrm{C})$<smiles>CC(C)=CC(=O)CC(C)c1ccc(C)cc1</smiles>

4. ar-turmerone<smiles>C=C1C=CC(C(C)CC(=O)C=C(C)C)CC1</smiles>

5. $\beta$-turmerone<smiles>CC(C)=CC(=O)CC(C)C1C=CC(C)=CC1</smiles>

6. $\alpha$-turmerone

Figure 1. Structures of three curcuminoids and three volatile compounds in turmeric.

\section{Results and Discussion}

\subsection{Optimization of PLE Procedure}

PLE has become a green sample preparation method for plant analysis due to its advantages of good repeatability, shorter extraction time, lower extraction solvent assumption, and higher extraction efficiency [26-28]. Schieffer [29] found that the contents of curcuminoids from PLE were higher than those from Soxhlet extraction and single or multiple ultrasonic extractions. PLE was also used for the extraction of volatile compounds in several Curcuma plants $[25,30]$. Thus, PLE was adopted for the extraction of both curcuminoids and volatile components in turmeric in the present research. 
The PLE procedure was optimized using a univariate approach. All variables involved in the procedure have been assayed: Solvent (methanol, ethanol, 50\% methanol, 50\% ethanol), temperature $\left(80-160^{\circ} \mathrm{C}\right)$, particle size $(0.125-0.45 \mathrm{~mm})$, static extraction time $(5,10,15 \mathrm{~min})$, and extraction cycles $(1,2,3$ cycles). Total peak areas of the six investigated compounds were used as a marker for evaluation of the extraction efficiency. According to the results of the optimization, the final conditions of the PLE method were: solvent, ethanol; temperature, $100^{\circ} \mathrm{C}$; particle size, $0.20-0.30 \mathrm{~mm}$; static extraction time, $5 \mathrm{~min}$; static cycle, 1 ; pressure, $1500 \mathrm{psi}$, and $60 \%$ of the flush volume.

\subsection{Optimization of Chromatographic Conditions}

The optimization of the HPLC conditions was performed using the mix reference compound solution and sample 8. Many HPLC methods have been developed for analyzing the three curcuminoids $[17,18]$, and the LC-MS method has been reported to identify the characteristic curcuminoids and sesquiterpenoids in turmeric [31]. However, we found that $\beta$-turmerone and $\alpha$-turmerone were hard to separate. Therefore, different types of columns, including C18 (Zorbax SB-C18 and Zorbax Extend-C18), Phenyl (Zorbax SB-Phenyl), and C8 (Phenomenex Luna C8), were tested. It was found that $\beta$-turmerone and $\alpha$-turmerone could be separated only on a Zorbax SB-C18 column among those tested columns. Different compositions of the mobile phase (methanol-water, acetonitrile-water, and acetonitrile-acid aqueous solution) and different column temperatures were also tested. As a result, acetonitrile and $0.4 \%$ aqueous acetic acid was chosen as the eluting solvent to achieve a better resolution and an acceptable tailing factor. It was also found that an increasing column temperature could improve the chromatographic behavior. The resolution increased and the retention time shortened with an increasing column temperature. At the column temperature of $35^{\circ} \mathrm{C}$, all six compounds were well separated (Figure 2). For the selection of the detection wavelengths, wavelengths from 200 to $800 \mathrm{~nm}$ were scanned. The UV maximum absorption wavelengths were chosen to monitor these analytes, i.e., $430 \mathrm{~nm}$ for the three curcuminoids and $240 \mathrm{~nm}$ for the three volatile compounds.

\subsection{HPLC Method Validation}

\subsubsection{Calibration, Limits of Detection, and Quantification}

The calculated results are given in Table 1 . The calibration curves of the six analytes showed good linearity $\left(R^{2}>0.9999\right)$ in a relatively wide concentration range. The limits of detection (LOD) and the limits of quantification (LOQ) of the six analytes were $0.20-0.91 \mu \mathrm{g} / \mathrm{mL}$ and $0.67-3.02 \mu \mathrm{g} / \mathrm{mL}$, respectively. The results indicated that the established method was sensitive enough for the quantification of the six analytes in turmeric.

Table 1. Calibration curves, limits of detection (LODs), and limits of quantification (LOQs) of the six analytes.

\begin{tabular}{cccccc}
\hline Analyte & Linear Equation $^{\mathbf{a}}$ & $\boldsymbol{R}^{\mathbf{2} \mathbf{b}}$ & $\begin{array}{c}\text { Linear Range } \\
(\mu \mathrm{g} / \mathrm{mL})\end{array}$ & $\mathbf{L O D}^{(\mu \mathrm{g} / \mathrm{mL})^{\mathbf{c}}}$ & $\mathbf{L O Q}^{(\mu \mathrm{g} / \mathrm{mL})^{\mathbf{d}}}$ \\
\hline Bisdemethoxycurcumin & $y=101,215 x-75,414$ & 0.9999 & $3.13-100$ & 0.20 & 0.67 \\
Demethoxycurcumin & $y=87,918 x-66,314$ & 1.0000 & $1.56-100$ & 0.26 & 0.88 \\
Curcumin & $y=86,839 x-64,613$ & 0.9999 & $1.56-100$ & 0.31 & 1.04 \\
ar-Turmerone & $y=26,801 x-33,652$ & 1.0000 & $6.25-400$ & 0.73 & 2.45 \\
$\beta$-Turmerone & $y=69,449 x-49,841$ & 1.0000 & $3.13-200$ & 0.51 & 1.71 \\
$\alpha$-Turmerone & $y=35,041 x-46,310$ & 1.0000 & $3.13-200$ & 0.91 & 3.02 \\
\hline
\end{tabular}

\footnotetext{
${ }^{\mathrm{a}} y$, peak area; $x$, concentration of the analytes $(\mu \mathrm{g} / \mathrm{mL}) ;{ }^{\mathrm{b}}$ the correlation coefficient; ${ }^{\mathrm{c}}$ limit of detection $(\mathrm{S} / \mathrm{N}=3)$;
}

d limit of quantification $(\mathrm{S} / \mathrm{N}=10)$. 

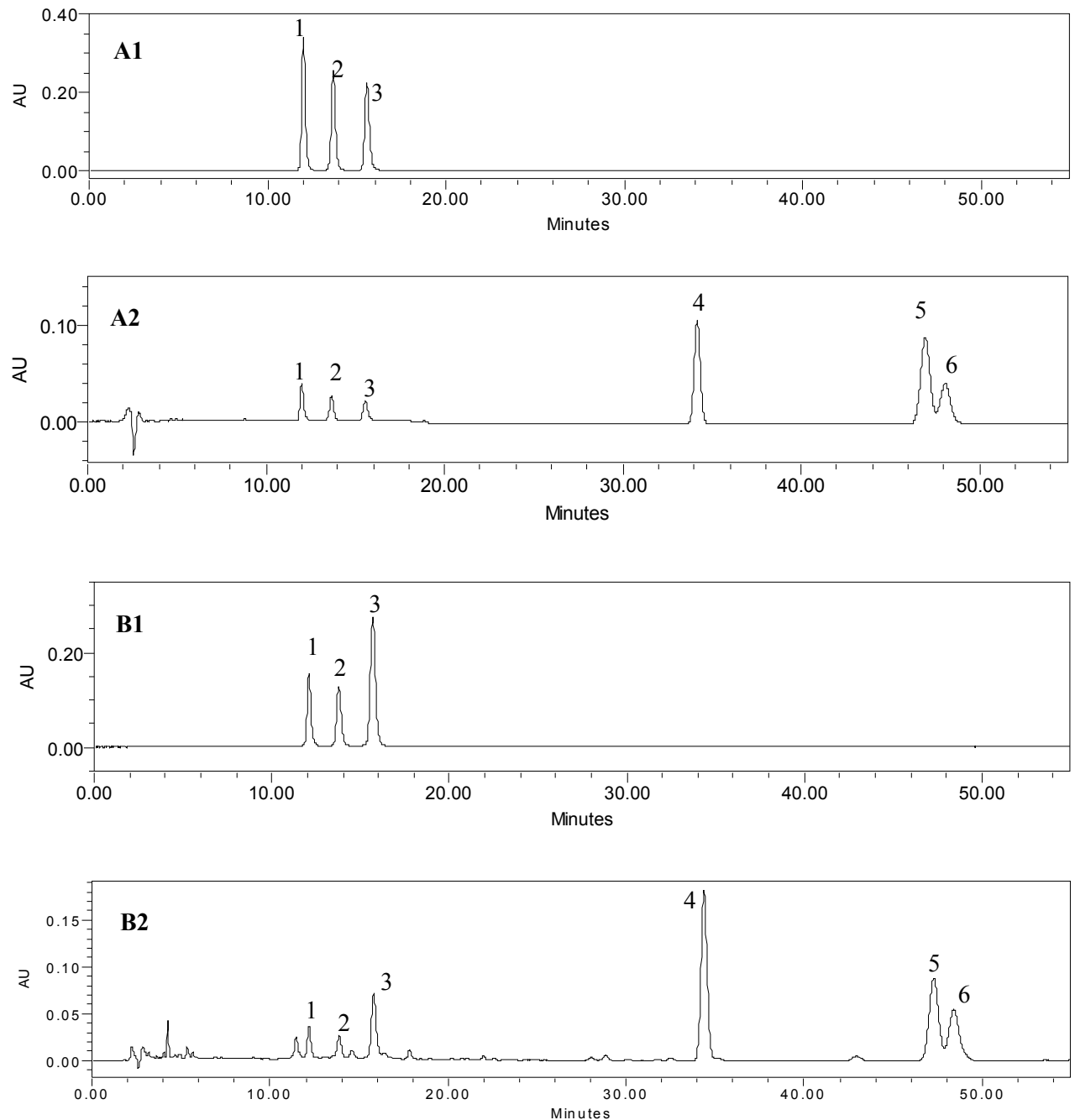

Figure 2. HPLC chromatograms of the mixed standards solution (A1: $430 \mathrm{~nm}, \mathbf{A 2}$ : $240 \mathrm{~nm}$ ) and turmeric sample (B1: $430 \mathrm{~nm}, \mathbf{B 2 :} 240 \mathrm{~nm})$. The peaks were numbered the same as those in Figure 1.

\subsubsection{Precision and Stability}

As shown in Table 2, the established method showed good precision for the quantification of the six analytes, with the relative standard deviation (RSD) of intra- and inter-day variations less than $2 \%$. For the stability test, the same sample solution was analyzed every $6 \mathrm{~h}$ for $48 \mathrm{~h}$ at room temperature. The results indicated that the analytes in the sample solution were stable over $48 \mathrm{~h}$, with RSDs less than $2 \%$.

Table 2. Precision and stability of the six analytes.

\begin{tabular}{|c|c|c|c|c|c|}
\hline \multirow{3}{*}{ Analyte } & \multicolumn{4}{|c|}{ Precision } & \multirow{3}{*}{$\begin{array}{c}\text { Stability }(n=8) \\
\operatorname{RSD}(\%)\end{array}$} \\
\hline & \multicolumn{2}{|c|}{ Intra-Day $(n=6)$} & \multicolumn{2}{|c|}{ Inter-Day $(n=6)$} & \\
\hline & $\begin{array}{l}\text { Detected } \\
(\mu \mathrm{g} / \mathrm{mL})^{a}\end{array}$ & RSD (\%) ${ }^{b}$ & $\begin{array}{l}\text { Detected } \\
(\mu \mathrm{g} / \mathrm{mL})\end{array}$ & RSD (\%) & \\
\hline Bisdemethoxycurcumin & $27.84 \pm 0.24$ & 0.86 & $27.59 \pm 0.32$ & 1.15 & 1.27 \\
\hline Demethoxycurcumin & $34.07 \pm 0.32$ & 0.93 & $33.70 \pm 0.41$ & 1.21 & 1.30 \\
\hline Curcumin & $120.94 \pm 1.16$ & 0.96 & $120.61 \pm 0.80$ & 0.66 & 0.92 \\
\hline ar-Turmerone & $114.21 \pm 0.75$ & 0.66 & $116.30 \pm 2.30$ & 1.98 & 0.17 \\
\hline$\beta$-Turmerone & $37.36 \pm 0.23$ & 0.62 & $38.22 \pm 0.77$ & 2.02 & 0.19 \\
\hline$\alpha$-Turmerone & $40.94 \pm 0.45$ & 1.10 & $41.37 \pm 0.56$ & 1.35 & 0.25 \\
\hline
\end{tabular}

${ }^{\mathrm{a}}$ All values are mean \pm S.D.; ${ }^{\mathrm{b}} \mathrm{RSD} \%=($ S.D. $/$ mean $) \times 100 \%$. 


\subsubsection{Accuracy}

The recovery test was used to evaluate the accuracy of the described analytical method. The mean recovery of the six analytes ranged from $93.24-104.83 \%$, with RSDs less than 5\% (see Table 3), which indicated that the accuracy of the established method is promisingly established for quality evaluation of turmeric.

Table 3. Recoveries for the assay of six analytes.

\begin{tabular}{|c|c|c|c|c|c|}
\hline Analyte & Original (mg) & Spiked (mg) & Found $(\mathrm{mg})^{a}$ & Recovery $(\%)^{b}$ & RSD (\%) \\
\hline \multirow[t]{3}{*}{ Bisdemethoxycurcumin } & 0.69 & 0.6 & 1.27 & 96.88 & 4.27 \\
\hline & & 0.7 & 1.34 & 93.24 & 2.43 \\
\hline & & 0.8 & 1.49 & 99.64 & 3.33 \\
\hline \multirow[t]{3}{*}{ Demethoxycurcumin } & 0.84 & 0.6 & 1.44 & 101.14 & 1.79 \\
\hline & & 0.8 & 1.68 & 104.83 & 0.99 \\
\hline & & 1 & 1.88 & 104.12 & 2.13 \\
\hline \multirow[t]{3}{*}{ Curcumin } & 3.01 & 2.5 & 5.61 & 104.22 & 3.75 \\
\hline & & 3 & 5.93 & 97.47 & 3.18 \\
\hline & & 3.5 & 6.56 & 101.43 & 1.74 \\
\hline \multirow[t]{3}{*}{ ar-Turmerone } & 2.84 & 2.20 & 5.02 & 99.21 & 2.60 \\
\hline & & 2.50 & 5.37 & 101.03 & 2.66 \\
\hline & & 3.00 & 5.70 & 95.35 & 2.99 \\
\hline \multirow[t]{3}{*}{$\beta$-Turmerone } & 0.93 & 0.80 & 1.71 & 98.11 & 3.39 \\
\hline & & 0.90 & 1.80 & 97.10 & 3.83 \\
\hline & & 1.00 & 1.90 & 96.59 & 4.68 \\
\hline \multirow[t]{3}{*}{$\alpha$-Turmerone } & 1.01 & 0.90 & 1.90 & 99.00 & 3.31 \\
\hline & & 1.00 & 2.00 & 99.00 & 3.68 \\
\hline & & 1.20 & 2.20 & 99.43 & 3.23 \\
\hline
\end{tabular}

${ }^{a}$ The data is presented as an average of three determinations; ${ }^{b}$ Recovery $(\%)=($ amount determined - amount original)/amount spiked $\times 100 \%$.

\subsection{Quality Evaluation of Commercial Turmeric Samples}

Using the calibration curve of each investigated compound, the six analytes in twelve turmeric samples were determined (Table 4). From Table 4, it was found that the levels of six individual analytes present in the samples varied considerably. The content of curcumin (at the range of $10.16 \mathrm{mg} / \mathrm{g}$ to $16.48 \mathrm{mg} / \mathrm{g}$ ) in all samples was the highest among the three curcuminoids, which meets the requirement (more than $10.0 \mathrm{mg} / \mathrm{g}$ in crude material and $9.0 \mathrm{mg} / \mathrm{g}$ in processed material) of China Pharmacopoeia [1]. However, the contents of the three volatile compounds were very different among different samples. $\alpha$-Turmerone $(3.54 \mathrm{mg} / \mathrm{g}$ to $30.27 \mathrm{mg} / \mathrm{g}$ ) was present in the highest content in the samples 3, 6, 9-12. The variety of the volatile compounds is much larger than that of the curcuminoids, which might be caused by the readily volatile property of the volatile compounds. It is well known that the quality of medicinal herbs can be influenced by many factors, such as the cultivating site, harvesting time, and post-harvest handling. Therefore, to obtain a consistent quality and efficacy of turmeric, it is suggested that all procedures involved in the production of this herb should be standardized. 
Table 4. Contents of three curcuminoids and three volatile compounds in commercial samples (mg/g).

\begin{tabular}{cccccccc}
\hline Sample & Collecting Region & BMC & DMC & C & ar-Turmerone & $\beta$-Turmerone & $\boldsymbol{\alpha}$-Turmerone \\
\hline 1 & Songzhou, Sichuan & $3.49 \pm 0.06$ & $4.98 \pm 0.12$ & $16.48 \pm 0.45$ & $12.43 \pm 0.44$ & $5.47 \pm 0.21$ & $8.19 \pm 0.33$ \\
2 & Songzhou-2, Sichuan & $3.69 \pm 0.08$ & $3.51 \pm 0.10$ & $11.67 \pm 0.23$ & $5.33 \pm 0.04$ & $4.00 \pm 0.03$ & $9.48 \pm 0.18$ \\
3 & Sichuan-1 & $3.11 \pm 0.05$ & $4.14 \pm 0.09$ & $12.23 \pm 0.54$ & $10.51 \pm 0.35$ & $7.64 \pm 0.11$ & $18.57 \pm 0.02$ \\
4 & Wenshan, Yunnan & $4.31 \pm 0.15$ & $4.99 \pm 0.10$ & $16.06 \pm 0.17$ & $10.38 \pm 0.39$ & $6.71 \pm 0.14$ & $15.88 \pm 0.44$ \\
5 & Sichuan-2 & $3.68 \pm 0.07$ & $4.90 \pm 0.11$ & $15.35 \pm 0.51$ & $8.01 \pm 0.03$ & $5.62 \pm 0.01$ & $12.67 \pm 0.05$ \\
6 & Sichuan-3 & $3.15 \pm 0.04$ & $2.64 \pm 0.05$ & $10.16 \pm 0.13$ & $4.74 \pm 0.09$ & $5.52 \pm 0.02$ & $16.91 \pm 0.28$ \\
7 & Guangzhou, Guangdong & $3.79 \pm 0.02$ & $5.82 \pm 0.05$ & $10.94 \pm 0.09$ & $11.68 \pm 0.18$ & $3.50 \pm 0.03$ & $3.54 \pm 0.04$ \\
8 & Shaoguan, Guangdong & $2.76 \pm 0.06$ & $3.35 \pm 0.06$ & $12.02 \pm 0.05$ & $11.36 \pm 0.03$ & $3.72 \pm 0.02$ & $4.04 \pm 0.03$ \\
9 & Zhanjiang, Guangdong & $2.86 \pm 0.02$ & $3.64 \pm 0.05$ & $11.47 \pm 0.38$ & $12.93 \pm 0.22$ & $8.92 \pm 0.14$ & $21.54 \pm 0.85$ \\
10 & Hanzhong, Shanxi & $3.63 \pm 0.05$ & $4.37 \pm 0.05$ & $14.32 \pm 0.11$ & $8.77 \pm 0.05$ & $9.77 \pm 0.08$ & $30.27 \pm 0.12$ \\
11 & Anguo, Hebei & $5.83 \pm 0.04$ & $7.60 \pm 0.09$ & $14.91 \pm 0.05$ & $11.88 \pm 0.05$ & $8.50 \pm 0.45$ & $19.55 \pm 0.34$ \\
12 & Yulin, Guangxi & $3.22 \pm 0.03$ & $4.50 \pm 0.01$ & $14.60 \pm 0.07$ & $11.04 \pm 0.02$ & $10.27 \pm 0.10$ & $29.16 \pm 0.24$ \\
\hline \multicolumn{7}{r}{} & The data is presented as an average of duplicates from two individual extracts for each sample.
\end{tabular}

\section{Materials and Methods}

\subsection{Chemicals and Materials}

HPLC grade methanol and acetonitrile were from J.T. Baker (Phillipsburg, NJ, USA). Acetic acid was purchased from Merck (Darmstadt, Germany). Ultra deionized water utilized in the study was obtained by a Milli-Q water purification system (Millipore, Billerica, MA, USA).

Turmeric samples were collected from different locations in China or purchased from local retailers in China, and were identified and authenticated as the rhizome of $C$. longa by Prof. Song-Lin Li from Jiangsu Province Academy of Chinese Medicine according to the standards of Chinese Pharmacopoeia [1]. The voucher specimens were deposited at the Institute of Chinese Medicine Science, Macau University, Macau SAR, China. The reference compound curcuminoids were isolated and purified by column chromatography on silica gel and Sephadex LH-20 columns, and three volatile compounds were isolated by the high speed counter-current chromatography (HSCCC) method from the rhizomes of $C$. longa [32]. Their structures were established by ${ }^{1} \mathrm{H}$ NMR, ${ }^{13} \mathrm{C}$ NMR, and MS spectral analysis. Their purities were analyzed to be all above $98 \%$ by HPLC.

\subsection{Chromatographic Conditions}

The separation was implemented on a Waters 2695 HPLC system (Waters, Milford, MA, USA), comprising a quaternary gradient pump, auto sampler, column oven, photodiode array detector, and data acquirement and processing was operated by the Waters Empower 2 software (Waters, Milford, MA, USA). The qualitative analysis was carried out on A Zorbax SB-C18 column $(250 \mathrm{~mm} \times 4.6 \mathrm{~mm}$ i.d., $5 \mu \mathrm{m})$ with a Zorbax SB-C18 guard column $(20 \mathrm{~mm} \times 4 \mathrm{~mm}, 5 \mu \mathrm{m})($ Agilent Technologies, Santa Clara, CA, USA). The column temperature was set at $35^{\circ} \mathrm{C}$. The mobile phase was composed of acetonitrile (A) and water containing $0.4 \%(v / v)$ acetic acid (B). The gradient program was as follows: $45 \% \mathrm{~A}$ at $0-13 \mathrm{~min}, 45-56 \% \mathrm{~A}$ at $13-16 \mathrm{~min}, 56 \% \mathrm{~A}$ at $16-50 \mathrm{~min}$, and $56-100 \% \mathrm{~A}$ at 50-55 $\mathrm{min}$. The re-equilibration duration was $10 \mathrm{~min}$ between individual runs. The flow rate was kept at $1.0 \mathrm{~mL} / \mathrm{min}$. The injection volume was $10 \mu \mathrm{L}$. An online detection wavelength was selected at wavelengths of $240 \mathrm{~nm}$ and $430 \mathrm{~nm}$.

\subsection{Pressurized Liquid Extraction (PLE)}

PLE were performed on a Dionex ASE 200 system (Dionex, Sunnyvale, CA, USA). The turmeric samples were dried at $50{ }^{\circ} \mathrm{C}$ for $24 \mathrm{~h}$ and then comminuted into a powder of $0.2-0.3 \mathrm{~mm}$. The turmeric sample $(0.5 \mathrm{~g})$ was mixed with diatomaceous earth $(0.5 \mathrm{~g})$ and placed into an $11 \mathrm{~mL}$ stainless steel extraction cell. The sample was extracted under the optimized conditions: Ethanol was used as the extraction solvent, temperature was set at $100{ }^{\circ} \mathrm{C}$; pressure was set at $1500 \mathrm{psi}$; and the sample was static extracted for $5 \mathrm{~min}$ by a flush volume of $60 \%$. Then, the turmeric extracts were transferred to a $50 \mathrm{~mL}$ volumetric flask and diluted to volume with ethanol. All sample solution was filtered through 
a $0.22 \mu \mathrm{m}$ membrane before use in the HPLC system. The above sample preparation procedure was repeated twice for each commercial turmeric sample for quantification.

\subsection{Preparation of Standard Solution}

The six reference compounds were accurately weighed and dissolved in methanol. The mixed standard solution containing all reference compounds was prepared in a $10 \mathrm{~mL}$ volumetric flask, diluting with methanol, and stored at $4{ }^{\circ} \mathrm{C}$. Subsequently, the stock solution was further diluted with methanol to obtain a series of concentrations of working solutions to establish calibration curves.

\subsection{Validation of the Quantitative Analysis}

The HPLC method described in this article was validated in terms of linearity, sensitivity, precision, stability, and accuracy. Six different concentrations of working solutions were analyzed in triplicate to establish calibration curves. The calibration curves of six analytes were constructed by plotting the mean peak areas vs. the concentration of the reference compounds. The limits of detection (LOD) and quantification (LOQ) were determined by injecting a series of dilute standard solutions until a signal-to-noise ratio $(\mathrm{S} / \mathrm{N})$ of 3 and 10 was obtained, respectively.

The precision test was performed by the measurements of intra- and inter-day variability. For the intra-day precision test, turmeric samples were extracted using the PLE method and analyzed for six replicates within one day, while, for the inter-day precision test, the samples were examined in duplicates for three consecutive days. Quantities of the analytes were calculated from their corresponding calibration curves. The RSD was used to evaluate the precision.

The stability test was performed by analyzing one sample at $0,2,4,6,8,12,24$, and $48 \mathrm{~h}$, respectively. Also, the RSD was taken as the measurements of stability. The accuracy of the method was determined by a spiked recovery test at three different concentration levels. Accurate amounts of mixed standard solutions at three different concentration levels (in the range of the calibration curve) were added into $0.25 \mathrm{~g}$ of the sample 8 powder, and then extracted and analyzed using the method as described above. The recovery was calculated with the following equation: Recovery $(\%)=($ amount determined - amount original $) /$ amount spiked $\times 100 \%$.

\section{Conclusions}

For the first time, a PLE and HPLC method was developed and validated to simultaneously quantify three curcuminoids (bisdemethoxycurcumin, demethoxycurcumin and curcumin) and three volatile compounds (ar-turmerone, $\beta$-turmerone, and $\alpha$-turmerone) of the rhizome of $C$. longa. This method was successfully applied for quantification of the two types of bioactive components in twelve turmeric samples, and was clarified to be a specific, sensitive, and accurate method for the quality control of turmeric. Inconsistency of these bioactive compounds among commercial samples was observed and it is suggested that all procedures involved in the production of this herb should be standardized to ensure consistent quality and, consequently, efficacy of turmeric.

Author Contributions: I.-C.C. performed the experiments and drafted the manuscript; C.-M.W. wrote and edited the paper; S.-P.L. and L.-G.L. analyzed the data; W.-C.Y. designed the research. Q.-W.Z. designed the research and wrote the paper. All authors reviewed and discussed manuscript.

Funding: This research was funded by Macau Science and Technology Development Fund (FDCT/042/2014/A1 and 013/2008/A1), National Key R\&D program of China (No. 2017YFC1703802), Ministry of Science and Technology of China (No. 2013DFM30080), and University of Macau (MYRG084-ICMS13-ZQW and MYRG2016-00046-ICMS-QRCM).

Acknowledgments: We appreciated Song-Lin Li at Jiangsu Province Academy of Chinese for the authentication of commercial turmeric samples and also thank Xiao-Qi Zhang and Ying Wang at the Jinan University for the assistance in collection of samples.

Conflicts of Interest: The authors declare no conflict of interest. 


\section{References}

1. Chinese Pharmacopoeia Commission. Pharmacopoeia of People's Republic of China; China Medical Pharmaceutical Science and Technology Publishing Press: Beijing, China, 2010; Volume 1, pp. 247-248.

2. Meng, F.C.; Zhou, Y.Q.; Ren, D.; Li, T.; Lu, J.J.; Wang, R.B.; Wang, C.M.; Lin, L.G.; Zhang, X.Q.; Ye, W.C.; et al. Turmeric: A review of its chemical composition, quality control, bioactivity, and pharmaceutical application. In Handbook of Food Bioengineering; Alexandru, M.G., Alina, M.H., Eds.; Academic Press: Cambridge, MA, USA, 2018; pp. 299-350.

3. Kunnumakkara, A.B.; Anand, P.; Aggarwal, B.B. Curcumin inhibits proliferation, invasion, angiogenesis and metastasis of different cancers through interaction with multiple cell signaling proteins. Cancer Lett. 2008, 269, 199-225. [CrossRef] [PubMed]

4. Aggarwal, B.B.; Harikumar, K.B. Potential therapeutic effects of curcumin, the anti-inflammatory agent, against neurodegenerative, cardiovascular, pulmonary, metabolic, autoimmune and neoplastic diseases. Int. J. Biochem. Cell Biol. 2009, 41, 40-59. [CrossRef] [PubMed]

5. Shi, L.; Fei, X.; Wang, Z. Demethoxycurcumin was prior to temozolomide on inhibiting proliferation and induced apoptosis of glioblastoma stem cells. Tumor Biol. 2015, 36, 7107-7119. [CrossRef] [PubMed]

6. Wang, R.; Li, Y.H.; Xu, Y.; Li, Y.B.; Wu, H.L.; Guo, H.; Zhang, J.Z.; Zhang, J.J.; Pan, X.Y.; Li, X.J. Curcumin produces neuroprotective effects via activating brain-derived neurotrophic factor/TrkB-dependent MAPK and PI-3K cascades in rodent cortical neurons. Prog. Neuro-Psychopharmacol. 2010, 34, 147-153. [CrossRef] [PubMed]

7. Ahmed, T.; Gilani, A.H. Inhibitory effect of curcuminoids on acetylcholinesterase activity and attenuation of scopolamine-induced amnesia may explain medicinal use of turmeric in Alzheimer's disease. Pharmacol. Biochem. Behav. 2009, 91, 554-559. [CrossRef] [PubMed]

8. Jayaprakasha, G.K.; Jaganmohan Rao, L.J.; Sakariah, K.K. Antioxidant activities of curcumin, demethoxycurcumin and bisdemethoxycurcumin. Food Chem. 2006, 98, 720-724. [CrossRef]

9. Gul, P.; Bakht, J. Antimicrobial activity of turmeric extract and its potential use in food industry. J. Food Sci. Technol. 2015, 52, 2272-2279. [CrossRef] [PubMed]

10. Apisariyakul, A.; Vanittanakom, N.; Buddhasukh, D. Antifungal activity of turmeric oil extracted from Curcuma longa (Zingiberaceae). J. Ethnopharmacol. 1995, 49, 163-169. [CrossRef]

11. Funk, J.L.; Frye, J.B.; Oyarzo, J.N.; Zhang, H.; Timmermann, B.N. Anti-Arthritic Effects and Toxicity of the Essential Oils of Turmeric (Curcuma longa L.). J. Agric. Food Chem. 2010, 58, 842-849. [CrossRef] [PubMed]

12. Lee, Y. Activation of apoptotic protein in U937 cells by a component of turmeric oil. BMB Rep. 2009, 42, 96-100. [CrossRef] [PubMed]

13. Park, S.Y.; Jin, M.L.; Kim, Y.H.; Kim, Y.; Lee, S.J. Anti-inflammatory effects of aromatic-turmerone through blocking of NF-kappaB, JNK, and p38 MAPK signaling pathways in amyloid beta-stimulated microglia. Int. Immunopharmacol. 2012, 14, 13-20. [CrossRef] [PubMed]

14. Lee, H.S. Chemical composition and antioxidant activity of fresh and dry rhizomes of turmeric Curcuma longa L. rhizome-derived ar-turmerone. Bioresour. Technol. 2006, 97, 1372-1376. [CrossRef] [PubMed]

15. Hucklenbroich, J.; Klein, R.; Neumaier, B.; Graf, R.; Fink, G.R.; Schroeter, M.; Rueger, M.A. Aromatic-turmerone induces neural stem cell proliferation in vitro and in vivo. Stem Cell Res. Ther. 2014, 5, 100. [CrossRef] [PubMed]

16. Yue, G.G.L.; Kwok, H.F.; Lee, J.K.M.; Jiang, L.; Chan, K.M.; Cheng, L.; Wong, E.C.W.; Leung, P.C.; Fung, K.P.; Lau, C.B.S. Novel anti-angiogenic effects of aromatic-turmerone, essential oil isolated from spice turmeric. J. Funct. Foods 2015, 15, 243-253. [CrossRef]

17. Jadhav, B.K.; Mahadik, K.R.; Paradkar, A.R. Development and validation of improved reversed phase-HPLC method for simultaneous determination of curcumin, demethoxycurcumin and bis-demethoxycurcumin. Chromatographia 2007, 65, 483-488. [CrossRef]

18. Syed, H.K.; Liew, K.B.; Loh, G.O.K.; Peh, K.K. Stability indicating HPLC-UV method for detection of curcumin in Curcuma longa extract and emulsion formulation. Food Chem. 2015, 170, 321-326. [CrossRef] [PubMed]

19. Jin, C.; Kong, W.J.; Luo, Y.; Wang, J.B.; Wang, H.T.; Li, Q.M.; Xiao, X.H. Development and validation of UPLC method for quality control of Curcuma longa Linn.: Fast simultaneous quantitation of three curcuminoids. J. Pharm. Biomed. 2010, 53, 43-49. 
20. Jiang, J.L.; Jin, X.L.; Zhang, H.; Su, X.; Qiao, B.; Yuan, Y.J. Identification of antitumor constituents in curcuminoids from Curcuma longa L. based on the composition-activity relationship. J. Pharm. Biomed. 2012, 70, 664-670. [CrossRef] [PubMed]

21. Paramasivam, M.; Poi, R.; Banerjee, H.; Bandyopadhyay, A. High-performance thin layer chromatographic method for quantitative determination of curcuminoids in Curcuma longa germplasm. Food Chem. 2009, 113, 640-644. [CrossRef]

22. Anubala, S.; Sekar, R.; Nagaiah, K. Development and validation of an analytical method for the separation and determination of major bioactive curcuminoids in Curcuma longa rhizomes and herbal products using non-aqueous capillary electrophoresis. Talanta 2014, 123, 10-17. [CrossRef] [PubMed]

23. Nhujak, T.; Saisuwan, W.; Srisa-art, M.; Petsom, A. Microemulsion electrokinetic chromatography for separation and analysis of curcuminoids in turmeric samples. J. Sep. Sci. 2006, 29, 666-676. [CrossRef] [PubMed]

24. Singh, G.; Kapoor, I.P.S.; Singh, P.; De Heluani, C.S.; De Lampasona, M.P.; Catalan, C.A. Comparative study of chemical composition and antioxidant activity of fresh and dry rhizomes of turmeric (Curcuma longa Linn.). Food Chem. Toxicol. 2010, 48, 1026-1031. [CrossRef] [PubMed]

25. Qin, N.Y.; Yang, F.Q.; Wang, Y.T.; Li, S.P. Quantitative determination of eight components in rhizome (Jianghuang) and tuberous root (Yujin) of Curcuma longa using pressurized liquid extraction and gas-chromatography-mass spectrometry. J. Pharm. Biomed. 2007, 43, 486-492. [CrossRef] [PubMed]

26. Mendiola, J.A.; Herrero, M.; Cifuentes, A.; Ibañez, E. Use of compressed fluids for sample preparation: Food applications. J. Chromatogr. A 2007, 1152, 234-246. [CrossRef] [PubMed]

27. Zhang, Q.W.; Lin, L.G.; Ye, W.C. Techniques for extraction and isolation of natural products: A comprehensive review. Chin. Med. 2018, 13, 20. [CrossRef] [PubMed]

28. Yi, Y.; Zhang, Q.W.; Li, S.L.; Wang, Y.; Ye, W.C.; Zhao, J.; Wang, Y.T. Simultaneous quantifcation of major favonoids in "Bawanghua", the edible fower of Hylocereus undatus using pressurised liquid extraction and high performance liquid chromatography. Food Chem. 2012, 135, 528-533. [CrossRef] [PubMed]

29. Schieffer, G.W. Pressurized liquid extraction of curcuminoids and curcuminoid degradation products from turmeric (Curcuma longa) with subsequent HPLC assays. J. Liq. Chromatogr. Relat. Technol. 2002, 25, 3033-3044. [CrossRef]

30. Zaibunnisa, A.H.; Norashikin, S.; Mamot, S.; Osman, H. An experimental design approach for the extraction of volatile compounds from turmeric leaves (Curcuma domestica) using pressurised liquid extraction (PLE). LWT-Food Sci. Technol. 2009, 42, 233-238. [CrossRef]

31. Karioti, A.; Fani, E.; Vincieri, F.F.; Bilia, A.R. Analysis and stability of the constituents of Curcuma longa and Harpagophytum procumbens tinctures by HPLC-DAD and HPLC-ESI-MS. J. Pharm. Biomed. 2011, 55, 479-486. [CrossRef] [PubMed]

32. Zhou, Y.Q.; Wang, C.M.; Wang, R.B.; Lin, L.G.; Yin, Z.Q.; Hu, H.; Zhang, Q.W. Preparative separation of four sesquiterpenoids from Curcuma longa by high-speed counter-current chromatography. Sep. Sci. Technol. 2017, 52, 497-503. [CrossRef]

Sample Availability: Samples of the compounds curcumin, bisdemethoxycurcumin, demethoxycurcumin, ar-turmerone, $\beta$-turmerone and $\alpha$-turmerone are available from the authors.

(C) 2018 by the authors. Licensee MDPI, Basel, Switzerland. This article is an open access article distributed under the terms and conditions of the Creative Commons Attribution (CC BY) license (http:// creativecommons.org/licenses/by/4.0/). 